\title{
A practical approach for reducing the risk of plastic shrinkage cracking of concrete
}

\author{
Sadegh Ghourchian ${ }^{a, b}$, Mateusz Wyrzykowski ${ }^{a}$, Pietro Lura ${ }^{a, b}$ \\ ampa, Swiss Federal Laboratories for Materials Science and Technology, Dübendorf, Switzerland \\ ${ }^{\mathrm{b}}$ Institute for Building Materials (IfB), ETH Zurich, Switzerland
}

Received: 08 December 2017 / Accepted: 15 December 2017 / Published online: 19 December 2017

(C) The Author(s) 2017. This article is published with open access and licensed under a Creative Commons Attribution 4.0 International License.

\begin{abstract}
In this letter, a conventional method for mitigation of plastic shrinkage of fresh concrete based on comparing bleeding and evaporation rates (the former based on the commonly observed values of bleeding rate and the latter estimated by means of the commonly-used $\mathrm{ACl}$ nomograph) is critically assessed. It is shown that even if the initial bleeding rates are sufficiently high (i.e. higher than the evaporation rates), cracking may still occur if all the bleed water is lost by evaporation between the times of initial and final set, leading to the rise of capillary pressure. An alternative and more conservative method should be thus based on the total (accumulated) amount of bleed water compared to the total amount of evaporated water. The former should take into account the concrete's properties and the geometry of the member, while the latter can be assumed based on the nomograph method.
\end{abstract}

Keywords: Fresh concrete; Plastic shrinkage cracking; Evaporation rate; Bleeding; Crack mitigation

\section{Introduction}

Fresh concrete after placing undergoes deformations that are due to settlement of solids in the mixture and further due to drying as water evaporates from the exposed surfaces. These deformations occur during the stage when concrete is still plastic and hence are referred to as plastic shrinkage. High magnitudes of plastic shrinkage together with low tensile strength at early age often lead to opening of large cracks that may seriously impair concrete service properties and its designed lifetime, see Fig. 1.

In the literature [1-7], plastic shrinkage cracking was primarily related to the evaporation of bleed water, leading to onset of capillary pressure and eventually cracking. In 1957, Lerch [1] stated that:

"Plastic shrinkage cracks develop shortly after the sheen disappears from the surface of concrete and when this type of cracking starts, it can be observed to proceed very rapidly."

The "sheen" mentioned by Lerch was due to the presence of water that flows towards the upper surfaces of concrete right after placement and accumulates on them in a process called bleeding.

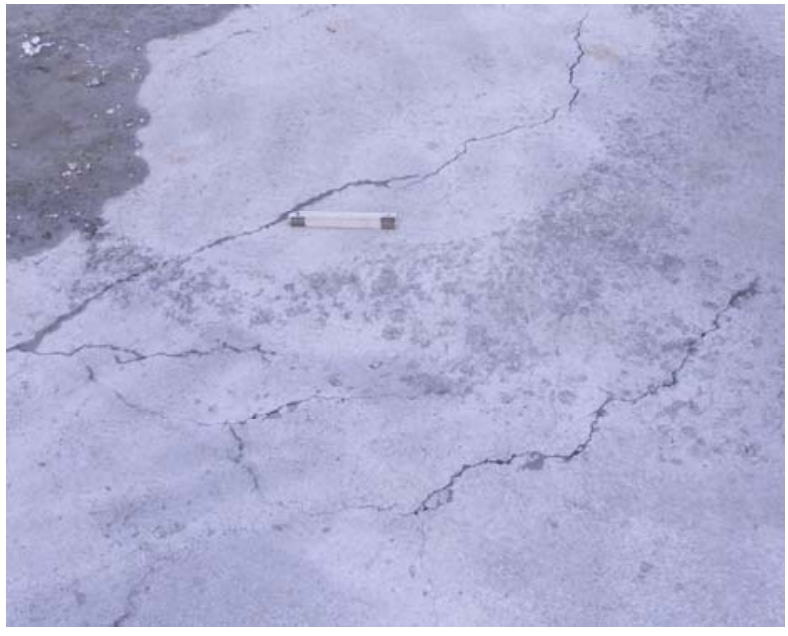

Figure 1. Plastic shrinkage cracks appearing on the concrete surface few hours after placement. Photo courtesy of Dr. Andreas Leemann, Empa.

Bleeding is due to self-weight consolidation of solids in the fresh concrete occurring due to the higher density of the solids compared to the density of the pore water $[8,9]$. The moment when the sheen at the concrete surface disappears indicates the complete evaporation of the bleed water. This happens a certain time after the evaporation rate has 
exceeded the bleeding rate, depending on the amount of bleed water that has accumulated on the surface and on the environmental conditions, see Fig. 2 . The fact that cracking is detected "soon after" [the evaporation rate exceeds the bleeding rate] was also reported by Menzel [10].

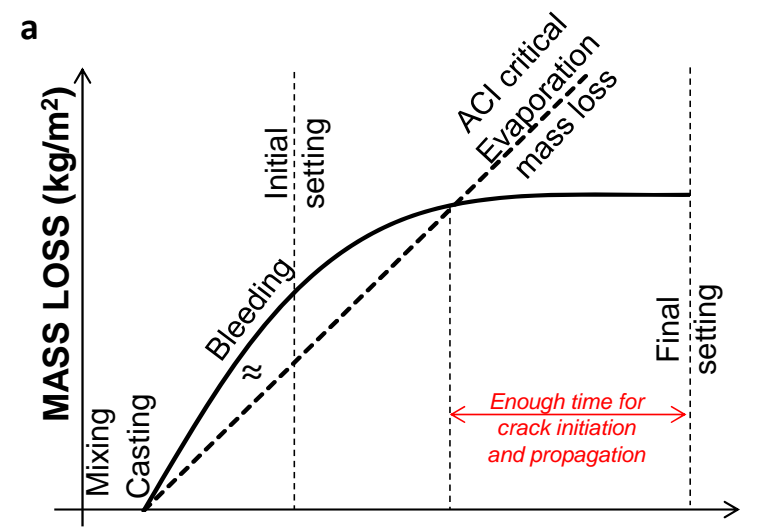

TIME (h)

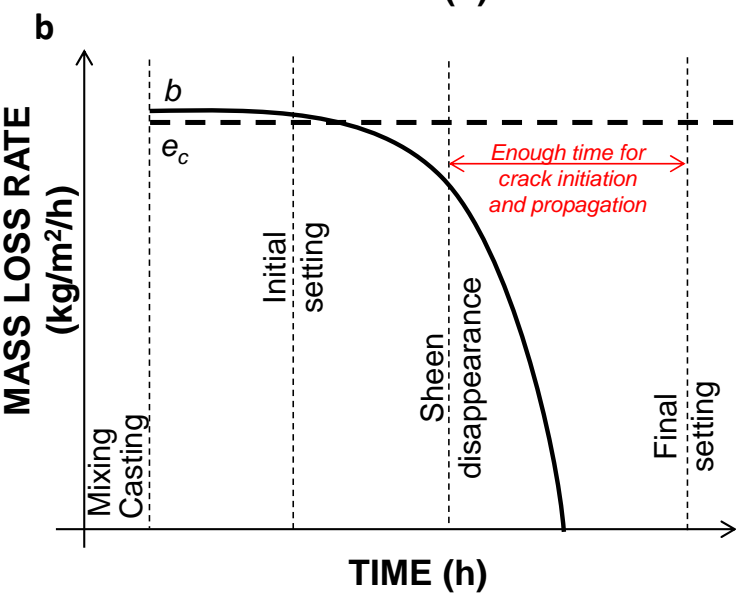

Figure 2. Water mass loss from the fresh concrete surface in time (acumulative, b-rate). The time gap between the times of initial and final set, in which plastic shrinkage cracking can occur after the sheen disappearance in the drying state, is indicated. $b$ and $e_{c}$ are the bleeding rate and the critical evaporation rate, respectively.

Therefore, many efforts have been made to estimate the moment at which this phenomenon occurs and to mitigate these fast-growing cracks by appropriate measures during construction [6,7]. Accordingly, ACl 305R-10 [7] proposed the well-known method based on ensuring that the evaporation rate is lower than the bleeding rate of concrete. The evaporation rate can be estimated with the nomograph shown in Fig. 3. This nomograph was based on methods used in hydrology for predicting the rate of evaporation from lakes and reservoirs. It is worthwhile to mention that the rate of evaporation of free water and bleed water from mortars during the constant evaporation rate period (CRP) are almost identical [11], while for concretes, due to their larger aggregate volume (corresponding to a lower volumetric water content) [12], the CRP evaporation rate is likely lower [13-15]. Therefore, the ACI nomograph is likely not able to provide accurate estimations of the rate of evaporation of concrete, at least not after the bleed water is removed completely from the surface of the concrete $[7,13,16]$. It is noticed that the CRP continues for some time after the disappearance of the bleed water from the concrete surface, as long as the concrete's intrinsic permeability is constant $[14,17]$. On the other hand, some studies showed that the evaporation rate of concrete samples during the CRP agreed well $[14,15]$, or was even higher [18] than estimations based on the nomograph. The latter can be accidental, due to the fact that the wind speed utilized for obtaining the nomograph is based on measurements at $0.5 \mathrm{~m}$ above the evaporating surface, and air temperature and relative humidity at a level approximately 1.2 to $1.6 \mathrm{~m}$ higher than the evaporation surface [7]. Therefore the $\mathrm{ACl}$ method should be only utilized when the appropriate wind speed data and test conditions are available [7].

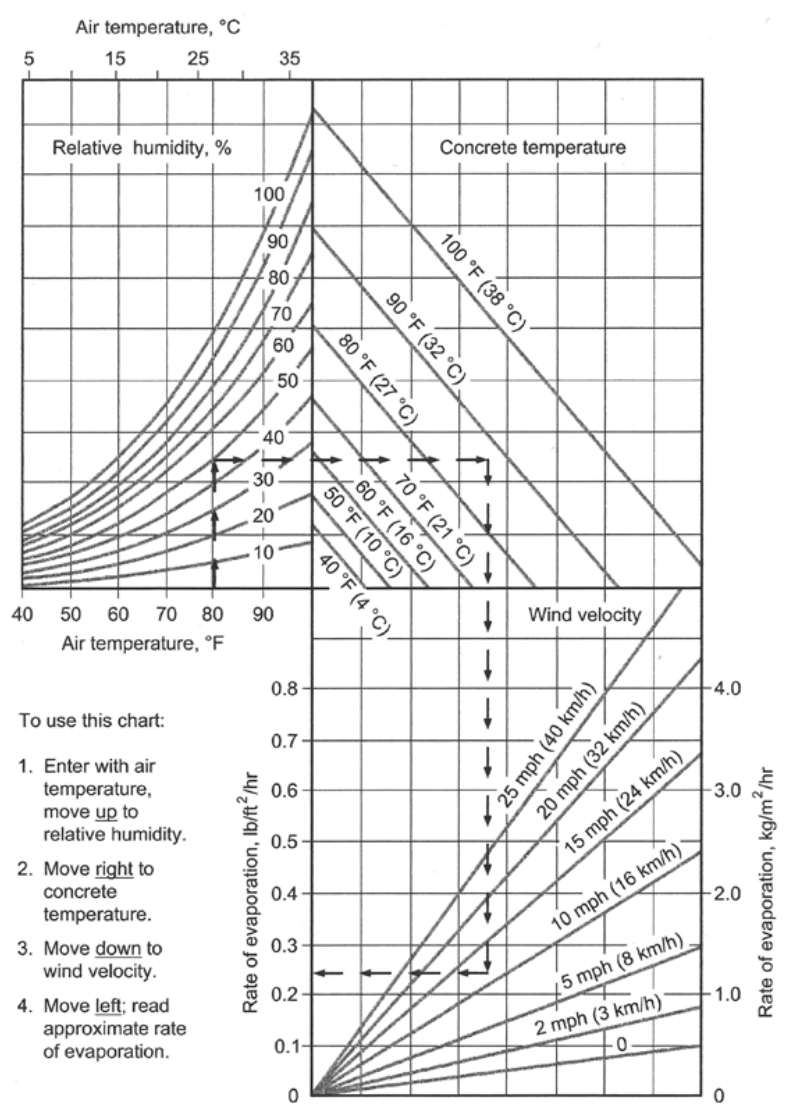

Figure 3. $\mathrm{ACl}$ nomograph for estimating the rate of evaporation of surface bleed water. Authorized reprint from ACl 305R-10 [7].

In addition, the actual temperature of the concrete at the time of casting needs to be utilized in the calculations and the changes of air temperature and relative humidity during casting and finishing of fresh concrete need to be taken into account [19]. Furthermore, the wind speed utilized in the calculations should not be based on transient gusts [7].

While the ACl method specifies a method for the estimation of the evaporation rate of free water (i.e. the water sink at the surface), there is no recommended estimation method for the bleeding rate of concretes. While the water sink depends primarily on the environmental conditions, 
the bleed water source depends mainly on the concrete itself and the height of the element $[10,20,21]$. Instead, the $\mathrm{ACl}$ method recommends only a value for the critical rate of evaporation: concrete placement is supposed to be safe when the evaporation rate is estimated to be below this value, or otherwise appropriate curing measures should to be implemented. According to the $\mathrm{ACl}$ method [7], commonly quoted values for normal concretes and silica fume containing concretes are $1 \mathrm{~kg} / \mathrm{m}^{2} / \mathrm{h}$ and $0.25 \mathrm{~kg} / \mathrm{m}^{2} / \mathrm{h}$, respectively. Moreover, for the state of New York and the city of Cincinnati, 0.75 and $0.5 \mathrm{~kg} / \mathrm{m}^{2} / \mathrm{h}$, were recommended, respectively [7]. Similarly, Canadian Codes and Australian references recommended 0.75 and $0.5 \mathrm{~kg} / \mathrm{m}^{2} / \mathrm{h}$, respectively [6]. These recommended critical evaporation rates originate from the fact that they are lower than the bleeding rates measured on concretes in a number of studies, e.g. $[6,9,20]$. Considering that Powers [9] observed bleeding rates in the range $1.1-4.1 \mathrm{~kg} / \mathrm{m}^{2} / \mathrm{h}$ (see also [6]), the limit of $1 \mathrm{~kg} / \mathrm{m}^{2} / \mathrm{h}$ appears to be conservative. However, the simplified approach with the assumed lower bound of bleeding rate described above can be criticized for the following reasons:

i. As also mentioned in the $\mathrm{ACl}$ method [7], concrete's bleeding properties can vary according to the permeability, the bulk modulus evolution and the height of the element, see also $[10,21]$. Therefore, the idea of specifying a maximum critical evaporation rate (or, inversely, a minimum concrete's bleeding rate) without explicitly considering these factors can lead to improper estimation of the cracking risk [15]. The bleeding rate (and as will be discussed later, the bleeding capacity) may be seriously reduced when using finer cements, fine fillers (e.g. silica fume), stabilizers, lower $w / c$, at higher temperature, see also $[5,7,20-23]$. Most of these factors were already recognized by Menzel [10].

ii. Even if the (initial) bleeding rate is higher than the evaporation rate according to the $\mathrm{ACl}$ recommendation, around the time of initial set the bleeding rate will invariably decrease, see Fig. 2. Consequently, the bleed water accumulated on the surface will be lost. If the removal of accumulated bleed water occurs before the time of final set, the corresponding onset of capillary pressure will lead to cracking. Since cracking proceeds rapidly, as mentioned already by Lerch [1], few minutes would be enough for crack propagation and severe damage. The results shown in $[18,24,25]$ are in line with the latter concept. The issue of the increased risk of cracking in the short time after bleeding stops ("critical period") was already raised by Menzel [10]. As long as the short time windows between the decrease of bleeding rate and the time of final set, together with the relatively high bleeding rates observed in many concretes, in the past usually assured that there was enough accumulated bleed water to avoid the rise of capillary pressures, the rate approach cannot be considered conservative, in particular for the concretes used nowadays. In addition to the lower bleeding rates (and thus lower bleeding capacity) mentioned in point $\mathrm{i}$, this is particularly because of the prolonged time window between the times of initial and final set caused by the application of plasticizers, or replacement of cement with inert fillers or with slow-reacting supplementary cementitious materials [14].

iii. Plastic shrinkage cracking is not limited to the cracks caused by the evaporation of pore water and capillary pressure. Even if we assume ideal external curing, which keeps the concrete surface saturated and postpones the evaporation of pore water until after the time of final set, a residual risk of cracking due to plastic settlement cracking (self-weight consolidation) remains due to the bleeding process itself [26-29].

It should be noted that the problem of cracking that may occur after evaporation of all bleed water (independently of the initial bleeding rate) in the critical period after bleeding stops was in fact recognized already by Menzel [10], see also [20]. Nevertheless, most likely due to complexity of the modeling approach to address this problem, a simple approach with fixed minimum bound of bleeding rate was adopted instead by $\mathrm{ACl}$ [7].

To address the complex problem of plastic shrinkage cracking, the strategy of modeling fresh concrete following a poromechanics framework has been used in the $\mathrm{PhD}$ project of the first author, see also $[14,17,21,30,31]$. In fact, the proposed model is able to couple the material properties and the geometry of a concrete element with the environmental factors, to finally estimate the cracking risk. In that project, the development of a poromechanics model has been accompanied by the design and interpretation of experiments targeted at assessing the material properties needed as input for the model. In addition, extensive experimental validation of the model was performed, taking different boundary conditions into account. Accordingly, based on these extensive studies, a simple mitigation method is presented in the next section, which is based on estimating the total capacity of bleed water and assuring that it remains higher than the total amount of the evaporated water until the time of final set. The total bleeding capacity can be estimated based on consolidation equation [8] that can be nowadays easily implemented in a numerical form, see [21].

\section{Improvement of the $\mathrm{ACl}$ nomograph approach based on the fresh concrete properties}

As mentioned in the previous section, the $\mathrm{ACl}$ method does not take into account the material properties. Therefore, here a simple method is presented which would allow to mitigate plastic shrinkage following the $\mathrm{ACl}$ approach but in a more effective way. As shown in Fig. 4, one can write eq. (1) to obtain the critical evaporation rate $\left(e_{c}\left[\mathrm{~kg} / \mathrm{m}^{2} / \mathrm{h}\right]\right)$ according to environmental conditions and material properties, to mitigate the plastic shrinkage cracking:

$$
e_{c}=\frac{C_{B}}{t_{F S B}-t_{\text {cast }}}
$$




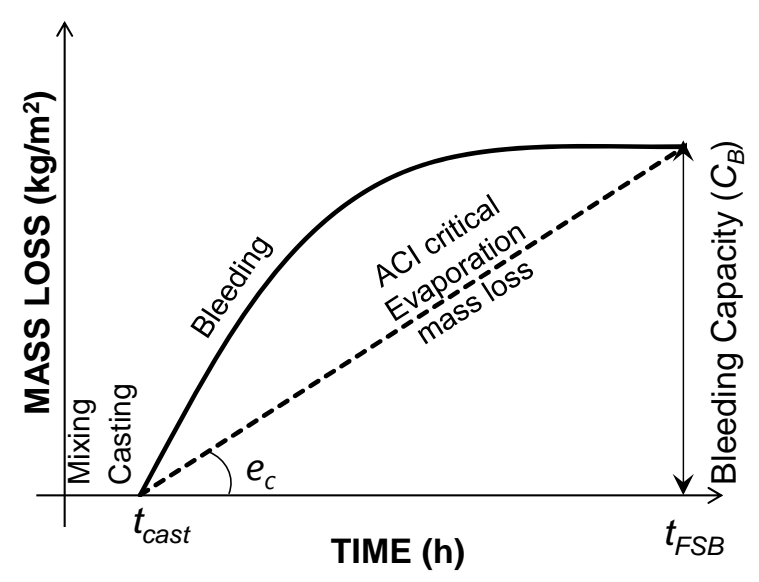

Figure 4. Estimation of the critical evaporation rate according to time of final set, time of casting and bleeding capacity

In eq. (1), $C_{B}\left[\mathrm{~kg} / \mathrm{m}^{2}\right]$ is the bleeding capacity, $t_{\text {cast }}[\mathrm{h}]$ is the time of casting, $t_{F S B}[\mathrm{~h}]$ is the time of final set in the bleeding state (covered sample with no evaporation). Therefore, by estimating the evaporation rate of the free bleed water in a construction project environment according to the $\mathrm{ACl}$ nomograph (Fig. 3), and comparing to the critical value of the evaporation rate $\left(e_{c}\right)$, one could mitigate cracking, by postponing the casting to when the evaporation rate is less than the critical value. The bleeding capacity is a function of the coefficient of permeability, bulk modulus and the height of the element, determinable according to the relatively simple numerical model of consolidation proposed originally by Terzaghi [8] with input data obtained from a simple bleeding test, see the recent work [21].

Another method is to design the fresh concrete according to the estimated average evaporation rate of the casting-tofinishing period by Fig. 3. In other words, according to eq. (2) one could obtain the required bleeding capacity that the concrete should possess. The design of a concrete mix with sufficiently high bleeding capacity determined with eq. (2) could be done by trial and error, employing a simple laboratory test for bleeding and the method proposed in [21]. There are also models available for estimating the time of final set [32], which can be used in eq. (2), coupled with the maturity concept to incorporate the effect of temperature $[17,33,34]$.

$$
C_{B}=e_{c}\left(t_{F S B}-t_{\text {cast }}\right)
$$

It is remarked that the time of set and the bleeding capacity are coupled, since both are a function of the mechanical properties. One practical approach would be to increase the coefficient of permeability (i.e. the bleeding rate) solely, since it is a function of the initial pore geometry independent of the evolution of mechanical properties [21], which can increase the bleeding capacity, while keeping the time of final set constant.

\section{Closing remarks}

This paper proposed new approaches to extend the applicability of the well-known ACl nomograph to avoid the risk of plastic shrinkage cracking by considering the total bleeding capacity instead of the bleeding rate. The method is based on determining the actual concrete's bleeding capacity (capacity of self-curing with bleed water) and assuring that the bleed water is present at the surface at given environmental conditions sufficiently long, at least until the time of final set. The effect of environmental conditions on evaporation of bleed water can be estimated with the $\mathrm{ACl}$ nomograph.

If under any circumstances, it was not possible to design the concrete according to the procedures proposed in this letter, or place the concrete in the proper time, external curing needs to be started latest at the time of the intersection of the critical evaporation mass loss and the bleeding as shown in Fig. 2. External curing methods include application of plastic sheets on the surface of concrete or spraying water on the whole surface [35]. The latter is necessary, since as mentioned by Lerch before, plastic shrinkage propagates very rapidly, and few minutes are enough for large cracks to occur. Furthermore, it must be assured that the whole concrete surface remains wet, otherwise cracking would occur in the zones with lack of external curing.

\section{References}

[1] W. Lerch, Plastic shrinkage, ACl 52nd Ann Conv, J ACl, Philadelphia, 1957, 797-802.

[2] D. Ravina, R. Shalon, Plastic shrinkage cracking, ACI J Proc, ACl, 1968.

[3] F.H. Wittmann, On the action of capillary pressure in fresh concrete. Cem Concr Res (1976) 6: 49-56. https://doi.org/10.1016/0008-8846(76)90050-8

[4] A. Radocea, A model of plastic shrinkage. Mag Concr Res (1994) 46: 125-132.

[5] M.D. Cohen, J. Olek, W.L. Dolch, Mechanism of plastic shrinkage cracking in portland cement and portland cement-silica fume paste and mortar. Cem Concr Res (1990) 20: 103-119. https://doi.org/10.1016/0008-8846(90)90121-D

[6] P.J. Uno, Plastic shrinkage cracking and evaporation formulas. $\mathrm{ACl}$ Mater J (1998) 95: 365-375.

[7] $\mathrm{ACl}$ Committee 305, ACl 305R-10: Guide to Hot Weather Concreting. $\mathrm{ACl}, 2010$.

[8] K. Terzaghi, Theoretical soil mechanics. Chapman And Hali, Limited John Wiler And Sons, Inc, New York, 1944.

[9] T.C. Powers, Properties of Fresh Concrete. John Wiley and Sons, Inc, New York (1968) 301.

[10] C.A. Menzel, Causes and prevention of crack development in plastic concrete. Proc Portland Cem Assoc (1954) 130-136.

[11] P. Lura, B. Pease, G.B. Mazzotta, F. Rajabipour, J. Weiss, Influence of shrinkage-reducing admixtures on development of plastic shrinkage cracks. ACI Mater J (2007) 104.

[12] E. Haghighi, E. Shahraeeni, P. Lehmann, D. Or, Evaporation rates across a convective air boundary layer are dominated by diffusion. Water Resour Res (2013) 49: 1602-1610. https://doi.org/10.1002/wrcr.20166

[13] M. Al-Fadhala, K.C. Hover, Rapid evaporation from freshly cast concrete and the Gulf environment. Constr Build Mater (2001) 15: 1-7. https://doi.org/10.1016/S0950-0618(00)00064-7

[14] S. Ghourchian, M. Wyrzykowski, L. Baquerizo, P. Lura, Susceptibility of Portland cement and blended cement concretes to plastic shrinkage cracking. Cem Concr Compos (2018) 85: 44-55. https://doi.org/10.1016/i.cemconcomp.2017.10.002

[15] H.-G. Kwak, S.-J. Ha, Plastic shrinkage cracking in concrete slabs. Part I: a numerical model. Mag Concr Res (2006) 58: 505-516. https://doi.org/10.1680/macr.2006.58.8.505 
[16] A.A. Almusallam, Effect of environmental conditions on the properties of fresh and hardened concrete. Cem Concr Compos (2001) 23: 353-361.

https://doi.org/10.1016/S0958-9465(01)00007-5

[17] S. Ghourchian, M. Wyrzykowski, P. Lura, A poromechanics model for plastic shrinkage of fresh cementitious materials. Cem Concr Res (2017, submitted).

[18] P. Ghoddousi, A. Raiss ghasemi, T. Parhizkar, A comparison between plastic shrinkage of concrete containing silica fume and the normal concrete. Int J Civ Eng IUST (2007) 5: 266-273.

[19] O.M. Jensen, Monitoring water loss form fresh concrete. Int RILEMJCI Semin Concr Durab Serv Life Plan, RILEM, 2006, 197-202.

[20] C.A. Menzel, A tribute to "Causes and Prevention of Crack Development in Plastic Concrete". ACl Spec Publ (2008) 249: 161172.

[21] S. Ghourchian, M. Wyrzykowski, P. Lura, The bleeding test: A simple method for obtaining the permeability and bulk modulus of fresh concrete. Cem Concr Res (2016) 89: 249-256. https://doi.org/10.1016/i.cemconres.2016.08.016

[22] D.P. Bentz, G. Sant, J. Weiss, Early-age properties of cement-based materials. I: Influence of cement fineness. J Mater Civ Eng (2008) 20: 502-508. https://doi.org/10.1061/(ASCE)0899-1561(2008)20:7(502)

[23] S.P. Shah, W.J. Weiss, W. Yang, Shrinkage Cracking--Can It Be Prevented? Concr Int (1998) 20: 51-55.

[24] A.A. Almusallam, M. Maslehuddin, M. Abdul-Waris, M.M. Khan, Effect of mix proportions on plastic shrinkage cracking of concrete in hot environments. Constr Build Mater (1998) 12: 353-358. https://doi.org/10.1016/S0950-0618(98)00019-1

[25] H.-G. Kwak, S.-J. Ha, Plastic shrinkage cracking in concrete slabs. Part II: numerical experiment and prediction of occurrence. Mag Concr Res (2006) 58: 517-532.

https://doi.org/10.1680/macr.2006.58.8.517

[26] H.-G. Kwak, S. Ha, W.J. Weiss, Experimental and numerical quantification of plastic settlement in fresh cementitious systems. J Mater Civ Eng (2010) 22: 951-966. https://doi.org/10.1061/(ASCE)MT.1943-5533.0000097

[27] R. Combrinck, W.P. Boshoff, Fundamentals of plastic settlement cracking in concrete. Constr Mater Struct Proc First Int Conf Constr Mater Struct, IOS Press, 2014, 354.

[28] C. Qi, J. Weiss, J. Olek, Assessing the settlement of fresh concrete using a non-contact laser profiling approach. Int Conf Constr Mater ConMat05, 2005.

[29] C. Qi, J. Weiss, J. Olek, Characterization of plastic shrinkage cracking in fiber reinforced concrete using image analysis and a modified Weibull function. Mater Struct (2003) 36: 386-395. https://doi.org/10.1007/BF02481064

[30] S. Ghourchian, M. Wyrzykowski, P. Lura, On the mechanism of plastic shrinkage cracking in fresh cementitious materials. Cem Concr Res (2017, submitted).

[31] S. Ghourchian, Plastic shrinkage cracking in concrete: from mechanisms to mitigation strategies. PhD Thesis, ETH Zurich, 2018.

[32] A.K. Schindler, Prediction of concrete setting. Proc RILEM Int Symp Adv Concr Sci Eng, Citeseer, 2004.

[33] D.P. Bentz, Activation energies of high-volume fly ash ternary blends: hydration and setting. Cem Concr Compos (2014) 53: 214 223. https://doi.org/10.1016/j.cemconcomp.2014.06.018

[34] L. D'Aloia, G. Chanvillard, Determining the "apparent" activation energy of concrete: Ea-numerical simulations of the heat of hydration of cement. Cem Concr Res (2002) 32: 1277-1289. https://doi.org/10.1016/S0008-8846(02)00791-3

[35] $\mathrm{ACl}$ 302.1R-04, Guide for Concrete Floor and Slab Construction. $\mathrm{ACl}$ 2004. 